\title{
Retrograde esophageal stenting for esophageal stenosis following esophageal atresia repair
}

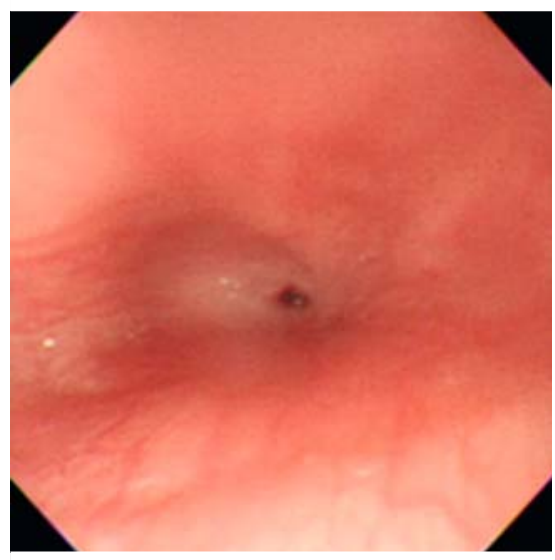

$\checkmark$ Fig. 1 Endoscopic view of the severe stenosis over the anastomosis.

A 3-month-old girl was admitted with vomiting following esophageal repair surgery to treat congenital esophageal atresia. Endoscopy revealed stenosis ( $\triangleright$ Fig. 1) over the anastomosis site, and she underwent three sessions of endoscopic balloon dilation. During the fourth session of esophageal dilation, dissection of the submucosal layer ( Fig.2) occurred after inflation of the balloon, and the procedure was postponed. The patient was subsequently fed via gastrostomy.

Follow-up endoscopy after 3 months revealed further stenosis of the anastomosis site and a guidewire could not be placed via the oral route. In a retrograde approach via the gastrostomy site, the guidewire was successfully passed over the stenosis proximally ( $\triangleright$ Fig. 3, \Video 1). A fully covered metal stent (Niti-S biliary covered stent, $10 \times$ $60 \mathrm{~mm}$; Taewoong Medical, Gyeonggido, South Korea) was successfully deployed over the guidewire via the oral route ( $\triangleright$ Fig. 4 ). The stent remained in place for 1 month and was removed smoothly ( $\triangleright$ Fig. 5).

Anastomotic stricture and leakage are the two most frequent complications that occur after esophageal atresia repair

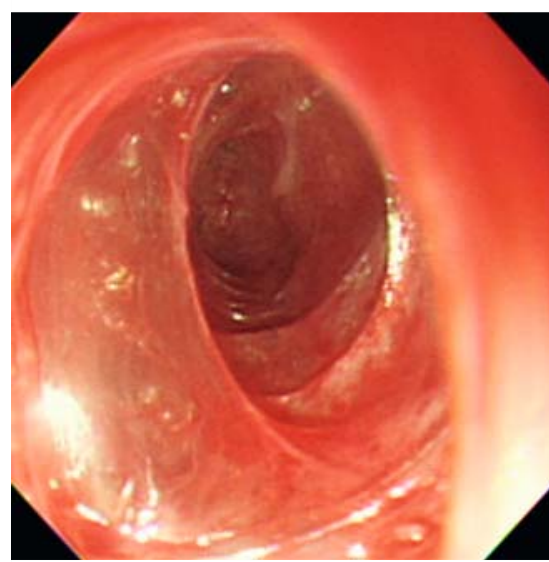

- Fig. 2 Endoscopic view of inadvertent dilation into the esophageal submucosal space.

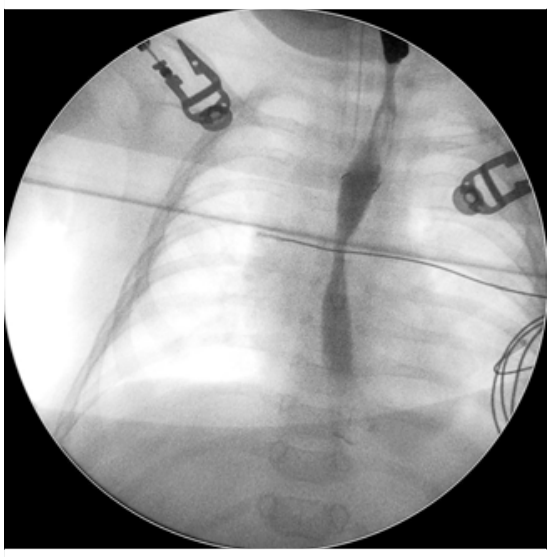

- Fig. 3 Fluoroscopic view after successful placement of a fully covered metal biliary stent over the anastomosis.

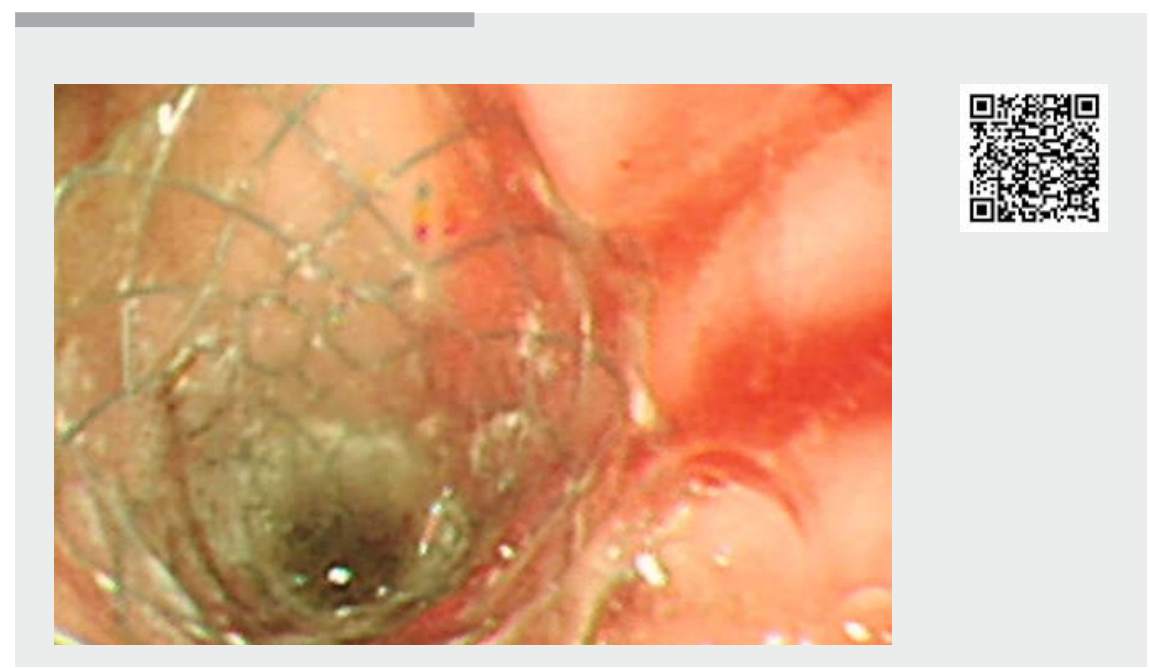

$\checkmark$ Video 1 Peroral endoscopy failed to reveal the anastomosis opening, and the guidewire could not be passed. Therefore, the endoscope was inserted via gastrostomy, the guidewire was placed using fluoroscopy, and the metal stent was deployed via the oral route.

[1]. Esophageal balloons are considered the preferred method to manage such complications via the oral approach, and metal stent placement is the preferred rescue therapy for refractory stenosis [2]. The present case involved a complication after esophageal dilation that may preclude subsequent endoscopic therapy, as the guidewire could not be passed via the oral route. The use of retrograde esophageal stenting as rescue therapy has been described for palliation of malignant obstruction [3] and fistula [4]. To the best of our knowledge, this is the first report to describe this technique to treat anastomosis stenosis in a case of esophageal atresia in an infant. 


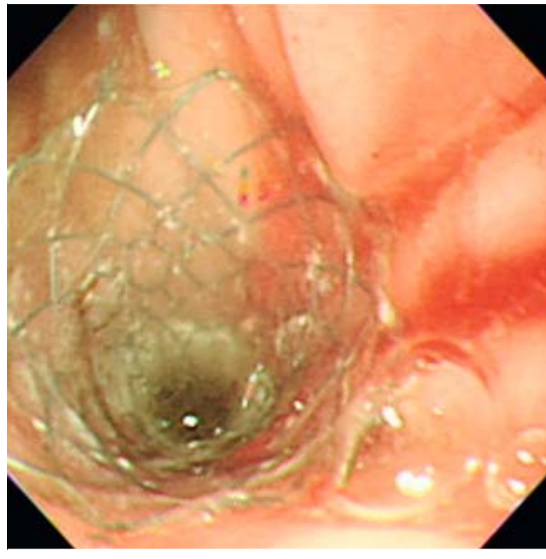

- Fig. 4 Endoscopic view from the gastric side of the stent.

Endoscopy_UCTN_Code_CPL_1AH_2AF

Acknowledgment

The authors received funding from the Changhua Christian Hospital (108-CCH-IRP-008) for this manuscript.

\section{Competing interests}

The authors declare that they have no conflict of interest.

The authors

Hsu-Heng Yen 1,2, ", Yu-Wei Fu', Yao-Jen Hsu3,

1 School of Medicine, Chung Shan Medical University, Taichung, Taiwan

2 Endoscopy Center, Division of Gastroenterology, Changhua Christian Hospital, Changhua, Taiwan

3 Department of Pediatric Surgery, Changhua Christian Hospital, Changhua, Taiwan

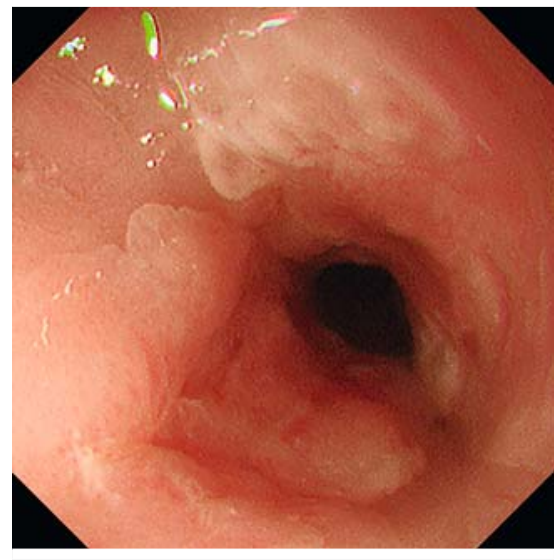

Fig. 5 Endoscopic view after removal of the metal stent.

\section{Corresponding author}

\section{Hsu-Heng Yen, MD}

Endoscopy Center, Division of

Gastroenterology, Changhua Christian

Hospital, 135 Nanhsiao Street, Changhua

500, Taiwan

Fax: +886-7-7228289

91646@cch.org.tw

\section{References}

[1] Fu YW, Hsu Y], Yen HH. Successful treatment of anastomotic leakage by endoscopic stenting after esophageal atresia repair in an infant. Endoscopy 2020. doi:10.1055/a1224-3477

[2] Ten KateCA, Tambucci R, Vlot J et al. An international survey on anastomotic stricture management after esophageal atresia repair: considerations and advisory statements. Surg Endosc 2020. doi:10.1007| s00464-020-07844-6
[3] Prachayakul V, Aswakul P, Kachintorn U. Complete obstructive esophageal cancer with esophagopleural fistula successfully treated by combined antegrade and retrograde rendezvous technique. Endoscopy 2011; 43: E354-E355

[4] Constantinescu G, Sandru V, Ilie M et al. Treatment of malignant esophageal fistulas: fluoroscopic placement of esophageal SEMS, endoscopically-assisted through surgical gastrostomy. A case report. J Gastrointestin Liver Dis 2016; 25: 249-252

\section{Bibliography}

Endoscopy 2021; 53: E370-E371

DOI 10.1055/a-1293-6515

ISSN 0013-726X

published online 26.11.2020

(C) 2020. Thieme. All rights reserved.

Georg Thieme Verlag KG, Rüdigerstraße 14, 70469 Stuttgart, Germany

\section{ENDOSCOPY E-VIDEOS}

https:/|eref.thieme.de/e-videos

回的 Endoscopy E-Videos is a free 然被 田: on interesting cases and new techniques in gastroenterological endoscopy. All papers include a high quality video and all contributions are freely accessible online.

This section has its own submission website at https://mc.manuscriptcentral.com/e-videos

\footnotetext{
* These authors contributed equally to this work.
} 